\title{
Communicating European Archives: Challenges, Strategies and Tools
}

\author{
DIETER SCHLENKER, DR. \\ Director Historical Archives of the European Union, via Bolognese 156, 50139 Firenze, Italy \\ e-mail: dieter.schlenker@eui.eu
}

\section{Introduction}

This article outlines the insights gained during the establishment of a communications strategy for the Historical Archives of the European Union (HAEU) in Florence. The article reflects on how key messages of a unique transnational European archives are construed from its mission, legal framework and in close collaboration with EU institutional archives services. It also sheds light on how to identify a specific European target audience for the Archives and other key elements of a communications strategy for a European archives.

The HAEU is the official home for the historical documents of the European Union Institutions, Bodies and Agencies. It is part of the European University Institute, a unique academic hub for doctoral and post-doctoral European studies. It houses, at Villa Salviati in Florence, seven kilometres of paper and digital archives as well as rich audio-visual and oral history collections documenting the historical process of European integration and cooperation. The EU-institutional archives are made accessible to the public after 30 years. ${ }^{1}$

The HAEU also hosts 160 deposits of private papers from eminent European political leaders, EU officials and pioneers in the European integration process, and a unique collection of archives of pro-European movements and non-EU organisations with a European scope, such as the European Space Agency and the European Free Trade Association. ${ }^{2}$

\section{Communication objectives}

The HAEU has a threefold mission: managing, preserving and making available to the public the historical archives of EU Institutions, Bodies and Agencies; acquiring, preserving and making accessible private archives of organizations and individuals that have played an important role in European integration; and raising the visibility, public recognition and usage of the EU Institutions' historical archives. Regulation:

Communication and information sharing is inscribed in the mission of the HAEU defined by EU

"The purpose of the deposit of the historical archives of the institutions at the EUI is to provide access to these archives from a single location, to promote their consultation and to stimulate research into the history of European integration and the European institutions."

The communications aspect is further specified in the Framework Partnership Agreement between the European Commission, acting for the EU Institutions, and the European University Institute, signed in 2015:

1. The Archives is ruled by Council Regulation (EU) 2015/496 of 17 March 2015 amending Regulation (EEC, Euratom) No 354/83 as regards the deposit of the historical archives of the institutions at the European University Institute in Florence: http://eur-lex.europa.eu/legal-content/EN/TXT/?uri=CELEX\%3A32015R0496.

2. For an overview on the archival deposits and the activities of the Archives see the brochure: Historical Archives of the European Union, Florence 2015: http://www.eui.eu/Documents/Research/HistoricalArchivesofEU/HAEU-BROCHURE-2015-2.pdf.

3. Cited from Article 7 of the preamble of EU Regulation 2015/496: https://eur-lex.europa.eu/legal-content/EN/TXT/?uri=uriserv:OJ.L_.2015.079.01.0001.01.ENG\&toc=OJ:L:2015:079:TOC. 
"In order to promote and facilitate access and consultation of the historical archives of the EU, the EUI will organise, alone or in collaboration with one or more depositing institutions, promotion actions such as exhibitions, symposia, programmes of grants for researchers, etc." ${ }^{4}$

This article focuses on information shared with the public, leaving aside reflections on the internal communication at the HAEU within the European University Institute. The key elements of a successful communications strategy are clearly defined objectives, key messages, and target audience. Additionally, it requires a set of means and tools that will be used to carry out those objectives.

In close collaboration with EU institutional archives services, the communications activities of the HAEU aim at supporting the operations, functions and services of the Archives, as well as raising its visibility and enabling the Archives to achieve its strategic goals. It strives to enhance the consultation of its collections, invite relevant organisations and individuals to deposit their papers, inform the depositors about academic and non-academic activities and raise the public awareness acknowledgement of the Archives at its seat in Villa Salviati, a culturally outstanding Renaissance villa in Florence.

In order to communicate professionally, pro-actively and with responsibility, the Archives uses a variety of channels and seeks to provide reliable, accurate, timely and clear information to its target audience.

\section{Key messages}

The key messages to be communicated to the public are that a) the HAEU preserves the collective memory of the European integration process and that it serves as a single, central access point to these unique primary sources and $\mathrm{b}$ ) that the Archives provides high quality archival preservation services to the EU Institutions and transparent access provisions for the interested academic and general public in a highly professional, multilingual and transnational research environment.

\section{Target audiences}

Taking into account a political space of 28, soon 27 Member states, with more than 500 million citizens, defining a European target audience for the Historical Archives of the European Union is a challenging task. The first target group consists of current or potential institutional or individual depositors. This community is based on more than 170 archival collections currently held at the HAEU. The group regards management and staff of EU Institutions, bodies and agencies, members and supporters of European federalist movements and associations, and staff of various non-EU organisations.

Communication directed at this group aims at highlighting the benefits of depositing archives at the HAEU, such as providing optimal preservation conditions for these papers, granting access to researchers and promoting the institutional memory for the general public. Depositing archives in an archival centre specializing on Europe is likely to contribute to the visibility and reputation of organisations and individuals as contributors to the process of European integration and cooperation.

Another target is the academic community, namely the dedicated European academic groups and networks, such as the 'History of European Integration Research Society (HEIRS)' and 'Réseau International de Jeunes Chercheurs en Histoire de l'Intégration Européenne (RICHIE)', the network of Jean-Monnet chairs on European studies and numerous University faculties with a focus on European contemporary history, European politics, economy and law. Communicating to these groups aims at increasing the consultation and usage of the archival collections.

Another target group concerns journalists of press and media in Europe. This is particularly relevant when the Archives organizes or hosts larger public events, such as the yearly Open Day, international academic conferences or events with high-level EU politicians' participation. Regional and local press are mainly interested in the local civic activities of the Archives, such as school programmes and local cultural events, such as concerts, art performances or documentary exhibitions.

Public interest in the Archives is raised through activities targeting citizens, cultural groups and

4. Cited from Annex 4.i of the 2015 FPA at: https://www.eui.eu/Documents/Research/HistoricalArchivesofEU/ Framework-Partnership-Agreement-SG-FPA-2015-1.pdf. 
school and relating to the key messages of the Archives. A pro-European message is particularly well received by the public when it involves hands-on experience with the European written memory and when combined with an appealing setup or a cultural activity of relevance.

A dedicated school programme and a prestigious seat in a classified Renaissance Villa, as is the case of the Historical Archives of the EU, are attractive levers to increase public interest in the Archives.

Finally the archival community, including archival associations and networks, is to be mentioned, as key messages can be shared locally, regionally and globally, and as there is interest in technical cooperation, participation in activities, workshops and events.

\section{Means of communication}

The transnational nature of the HAEU and its diverse target audiences across Europe and beyond require an orientation towards digital means of communication. The HAEU website, embedded in the website of the European University Institute, presents the primary window to the Archives for researchers, visitors and the interested public. The website is organized in a way to highlight present the Archives' mission and strategic goals, its archival collections, academic activities and public events, grant programmes and user services. As the HAEU's primary communication tool, the website is regularly updated with news articles in order to generate and maintain interest in the HAEU, its holdings and activities. A web-based newsletter informs the public about recent news and upcoming events, thereby attracting additional visitors to the web site.

The articles are written in a short and concise manner for quick reading, with a catchy title, keywords that can be captured by search engines and the main information gathered in the first paragraph answering the five 'W' questions: Who, What, Why, When and Where. Audiences for the news are diverse and the style and type of information must be adapted accordingly. Also, interviews with depositors, grant holders and political actors in visit to the Archives are prepared for the website to promote its key messages.

The website of the Archives is also partially available in French and Italian, in addition to English. The information is targeted to specific language groups. Adjustments are made to cater for different levels of knowledge about archival matters among the well-informed academic and institutional readership and the general public.

European and national press and media are mainly interested in newsworthy information. The Archives may use these communication channels at the occasion of particular political anniversaries, such as those of European Treaties (Rome, Maastricht, etc.) or at events with high-level political participation. Therefore only significant events, deposits and project activities qualify for press involvement.

Videos and photos are produced during events and visits and published in social media of the Archives in order to provide a visual impression and promote the Archives.

\section{Language}

An international audience requires a multi-faceted use of languages for communications. English is the main working language of the European University Institute to which the Archives pertains. On the other hand the European Union recognizes 23 official languages. EU Institutions produce their archival descriptions in French, which used to be the main working language of EU institutions. This gives French an important role in the field of archival research.

The Archives website is maintained in two languages, English and French. The readership of the French part of the site reaches about 10\% of the English audience. For communications on local events and activities and on projects organized jointly with local or regional partners, schools and cultural groups, Italian is used as the second language of communication.

The collection strategy of private archives has a certain impact on language, as the inventories are, in most cases, prepared in the working language of the organization or the language of the individual's country of origin. News articles on these archival collections are then published in English and the language of the depositor. 
Finally, a certain pragmatic approach prevails when sharing general information online in regards to the Archives. The Wikipedia presentation of the Archives was prepared in five languages: English, French, Italian, German and Spanish.

\section{Social media}

A Canadian study from 2013 on the use of social media in 648 Archives found that: "with a few exceptions, archives were making minimal use of social media to attract users, user engagement was still relatively low, and the participants in the study had a number of concerns about contributing to social media."

However, in the same study, participants "saw the potential for social media to democratize the archives, contribute to the public good, allow for a richer historical record showing different points of view, and, ultimately, increase their engagement with archives."

In 2010, the US National Archives published its first social media strategy and in 2015 more than 200 National Archives staff contributed to 130 social media accounts, generating over 250 million views. For NARA, social media are used to tell stories, connect deeper and widen the audience and use more opportunities for civic engagement. ${ }^{7}$

The HAEU started using social media channels in 2014, with a Facebook account. It later also established a Twitter account, in order to reach out to new audiences and to offer more interactive ways of communications. The use of audio-visual platforms, such as Flickr, were also used regularly for wider dissemination of photo material, particularly from events, visits and the educational programme to a younger, non-academic audience. A Linkedin account was also established in order to specifically reach to the academic community. Through this account, the HAEU advertises its various training activities, as well as its grants.

Through its social media accounts, the Archives reaches its audiences more directly. They provide platforms for exchange and two-way communications, particularly through the use of hashtags and social media challenges (particularly on Twitter). While being aware that each social media channel has a specific audience, the Archives aims at adjusting accordingly to ensure that all the target audiences of the HAEU are properly reached. The social media presence will certainly see further developments in the future, such as a presence in Instagram.

\section{Printed material}

For communications to an international audience, printed materials have a secondary role. Nonetheless, they respond to concrete needs to inform on-site individual or group visitors, academic and political conference participants and participants at public events and open days. Each print product merits an analysis of its key audience and a reflection on the relevant language(s) of its production. A general brochure on the mission, holdings and activities of the Archives, flyers on specific activities, events or projects, posters and panels for events and exhibitions, are attractive for on-site visitors. Fact sheets provide relevant statistical figures on the Archives and are useful for press and for inter-archival cooperation. Relevant print materials are gathered in press kits and handed out to journalist attending events at the Archives. Through the Archives website, the printed material is also made available to remote audiences.

Regular exhibitions of original or facsimile archival documents and images promote the collections, enlarge the public interest in the Archives and provide excellent opportunities for cooperation with EU institutional archives and other external partners. Thematic exhibits of documents on-site in the Archives premises accompany and enrich conferences and events. Travelling exhibitions are prepared at the occasion of European anniversaries and major international events. All exhibits are in parallel prepared as online exhibitions available on the Archives website and promoted through social media channels.

5. Cited from Wendy M. Duff, Catherine A. Johnson and Joan M. Cherry: Reaching Out, Reaching In: A Preliminary Investigation into Archives' Use of Social Media in Canada, in: Archivaria 75(2013) p. 77.

6. Ibidem, p. 77.

7. NARA 2017-2020 Social Media Strategy at: http://usnationalarchives.github.io/social-media-strategy/introduction/. 


\section{Educational and cultural programmes}

Educational and cultural programmes are not strictly considered communications activities, but their impact on communicating the Archives, its mission, expertise and services, in particular to local and regional audiences, cannot be underestimated. Further to the important educational aspect, programmes for schools have an amplifier effect as they reach audiences, especially families, that the Archives otherwise could reach with difficulty. ${ }^{8}$

Cultural visits to the Archives for local and regional associations, foundations and clubs should be considered part of the range of communication and outreach activities. The Association 'Friends of the Historical Archives of the European Union' promotes and supports the activities of the Archives. It brings new audiences closer to the Archives, provides networking opportunities with current and potential depositors, colleagues and the interested academic community.

\section{Conclusion}

The main elements that need to be considered when establishing a communications strategy for Archives working in an European transnational environment, in particular the formulation of key messages and the identification of target audiences, have been outlined in this article. The communications strategy of the HAEU, which acts as the official home for the historical archives of the European Union Institutions, Bodies and Agencies, is derived from its mission of preserving and rendering accessible in a central point the EU historical archives, of acquiring non-EU and private archives related to the process of European integration and finally of raising the visibility, public recognition and usage of the EU archives. The strategic approach needs regular review and adaptation to the changing communication environment, in particular in the digital area and social media. Different channels and types of communications target a variety of audiences stretching from local to the international communities.

The task of communicating, reaching out and informing the public has been inscribed in the legal framework of the Archives. Communications therefore support the operations, functions and services of the Archives and enable the Archives in achieving its strategic goals. 